\title{
Study on vibration threshold of the elevator in Vietnam
}

\author{
Luu Thanh Tung
}

\begin{abstract}
Nowadays, elevators are installed for most of buildings and they are familiar with everyone in modern life. Thus, the elevators are required smoother and quieter. However, elevator manufacturing factories have no method and equipment to measure vibration in elevators. This paper introduces a method using an accelerometer and Fast Fourier Transform (FFT) to recognize vibration spectrum. This spectrum will be compared with standard one built by the manufacturer. In this paper, the standard spectrum of well-known elevator manufacturers such as Otis, Schindler etc. will be introduce (introduced?) for reference of Vietnamese elevator manufacturer.
\end{abstract}

Index Terms - FTT, vibration amplitude.

\section{INTRODUCTION}

$\mathrm{N}$ ew buildings in cities, not only commercial, but hotels and residential blocks are rising higher than ever. Architects are driven to design skyscrapers due to expensive land cost. These buildings require elevators run at super high speeds so as to save travel times within the buildings. To meet this requirement, some elevator manufacturers have in recent years developed technologies to allow elevators to achieve speed as high as $810 \mathrm{~m} / \mathrm{min}(13.5 \mathrm{~m} / \mathrm{s})$. The increase in speed of elevator does not only lead to riding comfort problem for passengers inside lift car while also caused a series of problems in regards to the generation of noise and vibration in the elevators [1].

Most nowadays elevators consist of an electric traction engine pulling on wire ropes attached to the top of the lift car. The motor unit is often

Manuscript Received on October 27th, 2016, Manuscript Revised February 27th, 2017

Luu Thanh Tung - Ho Chi Minh City University of Technology, Vietnam National University - Ho Chi Minh City. (e-mail: ttluu@hcmut.edu.vn). located on top of the building in a dedicated penthouse lift room. Air-borne noise from lifts has generally never been a problem. Typical noise levels inside lift plant rooms being around $70-80$ $\mathrm{dB}$ for modern elevator machines. This noise level could easily be attenuated by concrete slabs and walls which make up the lift motor room [2].

The problem is how to measure the vibration and with vibration date measured which elevator is better. In [3], an equipment to measure the movement of elevator is introduced. This equipment shows vibration in 3 axes $\mathrm{X}, \mathrm{Y}, \mathrm{Z}$. The results of data are the amplitude of the accelerations of 3 axes and the data can be used to calculate parameters to compare comfort and smoothness among elevators. A study [4] makes an elevators smoother by using a simple and effective acceleration feedback control method which is proposed for enhancing the riding comfort of the elevator. The proposed method employs a speed controller incorporating an acceleration feedback controller. The actual acceleration feedback measured by an accelerometer equipped in car is employed in the proposed control strategy. Theoretical analyses of the proposed method in [4] are to use FFT and the validity of the proposed method is proved through the experiments carried out at the elevator test tower. Another study [5], the experiments discussed in [5] take place in the UCLA Doris and Louis Factor Building, a 17- story steel-frame structure on the UCLA campus. Following the 1994 Northridge earthquake, the U.S. Geological Survey, in partnership with the UCLA Center for Embedded Networked Sensing (CENS), deployed a 72-accelerometer seismic array throughout factor, making it one of the most heavily instrumented buildings in North America. In [5], they used four accelerometer channels per floor two horizontal NS and two horizontal EW components. Then they used the FFT to analyze the signal received and decide vibration modes for simulation the tower and elevators. 
In this paper, the method to archive the amplitude of acceleration will be introduced. In addition, the threshold of comfort and discomfort in elevator is also shown. Three accelerometers are installed to measure the acceleration amplitude in 3 axes $\mathrm{X} \mathrm{Y}$ $Z$. The acceleration amplitude is a function of time, thus it is difficult to compare vibration amplitude among the elevators. The FFT will be introduced to solve this problem and the paper also shows a threshold of vibration of the famous elevator manufacturer and then help compare the quality of domestic elevators with that of foreign brand elevators. Next content, this paper is divided into 4 parts: FFT methodology, Whole body vibration, Vibration Criteria of elevators, Experiment of measuring the vibration and conclusion of this paper.

\section{FFT METHODOLOGY}

In the elevator, 3 accelerometers are installed together in a small box. The signals from 3 sensors is recorded and analyzed. To analyze the signals, the FFT methodology is often used. The FFT being from Fast Fourier Transform is one of the most important algorithms in signal processing and data analysis. FFT is introduced by Cooley and Tukey (1915 - 2000) [6]. Where, FFT is an algorithm which based on the Fourier transform but it allowed for significantly reducing the computational burden of practical spectral estimation. The Fourier Transform is a tool that breaks a waveform (a function or signal) into an alternate representation, characterized by sine and cosines. The Fourier Transform shows that any waveform can be re-written as the sum of sinusoidal functions, the Fourier Transform of a function is defined by $\mathrm{Eq}$ (1).

$$
G(f)=F[g(t)] \int_{-\infty}^{+\infty} g(t) e^{-2 \pi f t} d(t)
$$

The result is a function of $\mathrm{f}$, or frequency. As a result, $G(f)$ gives how much power $g(t)$ contains at the frequency $f$. From a time domain, a frequency domain is obtained by using FFT. This means that when the measuring signal of the accelerometer is in time domain (Fig. 1), they will be then transformed into frequency domain (Fig. 2). In the Fig. 2, frequency spectrum will show the vibration frequencies which appear in the cabin and their acceleration amplitude.

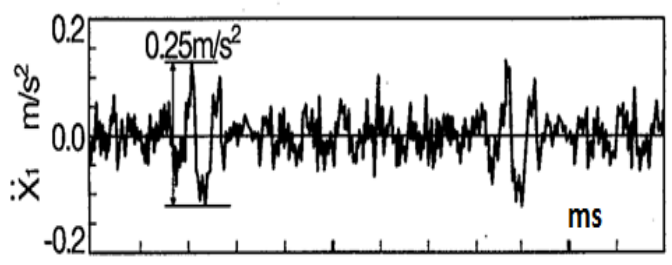

Fig 1. Transient response of cabin acceleration (Time domain) [6].

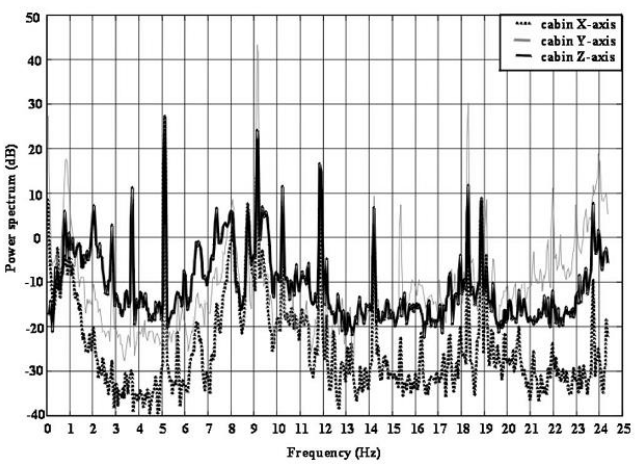

Fig 2. Spectrum of frequency from response of the acceleration [7].

\section{WHOLE BODY VIBRATION.}

Whole-body vibration is capable of producing a wide variety of different effects. It can generate a range of subjective sensations which can be quantified in many different ways. Both simple and complex activities can be disturbed by vibration affecting the various components of a task, from the input of information to the body (e.g. vision) through to the output of information from the body (e.g. hand control). Physiological parameters may be disturbed by vibration with either transitory effects or permanent changes. Vibration also causes a range of physical movements of parts of the body which may be quantified by objective methods and simulated in mathematical equations or with anthropodynamic dummies [8].

The study of human response to vibration is concerned with establishing relationships between various effects (e.g. impaired comfort, activities or health) and their causes (e.g. vibration conditions, other environmental conditions, or subject characteristics). With an endless range of potential effects and, frequently, very complex causal conditions, it cannot be hoped that knowledge will become complete, but that it will merely become sufficient to assist in the solution of problems. 


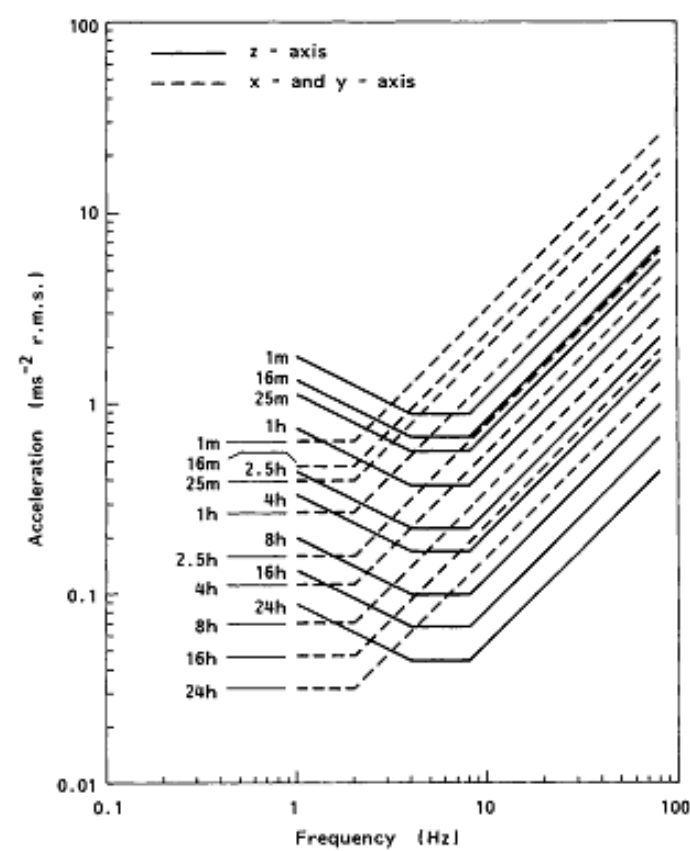

Fig 3. Reduced comfort boundaries for translational vibration as defined in International Standard 2631 [8].

During sinusoidal vertical oscillation at frequencies about $2 \mathrm{~Hz}$ most parts of the body move up and down together. The immediate sensation is of alternately being pushed up and then floating down. The eyes are able either to view objects moving with the body or to compensate for the motion and look at non-moving objects. Free movements of the hand may be disturbed causing some interference with handpositioning activities. If the motion has a frequency below about $0.5 \mathrm{~Hz}$ it may eventually cause symptoms of motion sickness: sweating, nausea or vomiting.

The boundaries of comfort and discomfort are shown in Fig. 3. When the human works with vibration, the acceleration amplitude should be under the boundaries. However, in elevators, the vibration amplitude requires higher criteria. The reason is the elevators are always in very high positions compared with the ground, if the elevators vibrate so much, the people inside elevators feel very nervous. Thus, the vibration and noise in elevators are much less than that in car or other transportation. The famous elevator brands only refer principle of measuring vibration and vibration analysis as shown in part 2. They also base on the result of human vibration in Fig. 3 but they often give criteria for themselves. Some elevator manufacturing companies do not announce the vibration criteria to the consumers.

\section{VIBRATION CRITERIA OF ELEVATORS.}

There are about 10 most famous elevator brands in the world. Some names can be listed such as Dover, Fujitec, Kone, Otis, Schindler .... These companies have own criteria for their elevators, and only some companies show their criteria of vibration boundary which human feels comfortable in elevators. The Fig. 4 shows the information about noise and vibration in Schindler [9]. Noise and vibration aspects of a Schindler elevator system cover the following areas:

- Ride quality: sound and vibration inside the car

- Air-borne noise, e.g. door noise, noise in the elevator shaft

- Structure-borne noise in walls: important, as it radiates sound into adjacent rooms.

In the Schindler elevators criterion, it is different from Fig. 3, there is no experience time in the elevators. It is due to time in the elevator calculated from start to end. In reality, the elevator installers use an accelerometer in 3 axes to measure the vibration amplitude and then use an equipment to invert these signal into frequency domain as written in part 2. After that, they will compare the result with Schindler criteria (Fig. 4) and decide that the vibration and noise are acceptable or unacceptable.
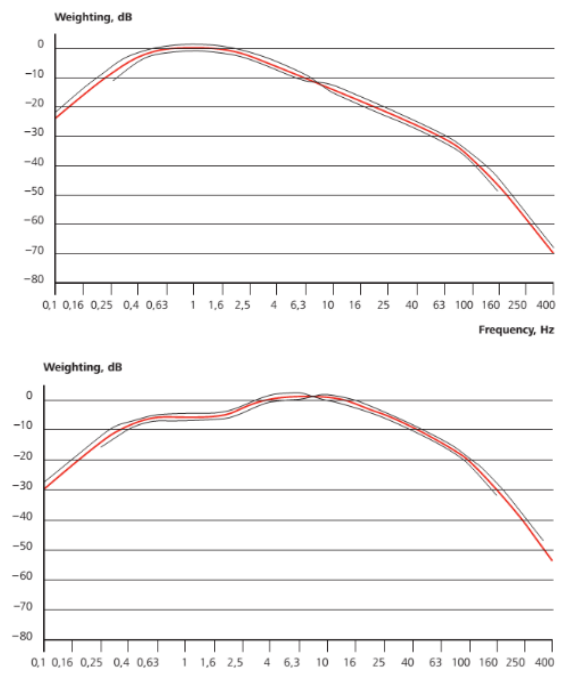

Frequency, $\mathrm{Hz}$ (b)

Fig 4. Vibration criteria in horizon vibration (a) and vertical one (b) [9]

The Kone elevator manufacturer has slogan "KONE Ride Comfort - quieter smoother elevator operation". The Kone manufacturer only shows acceleration amplitude for ride comfort (Fig. 5). 


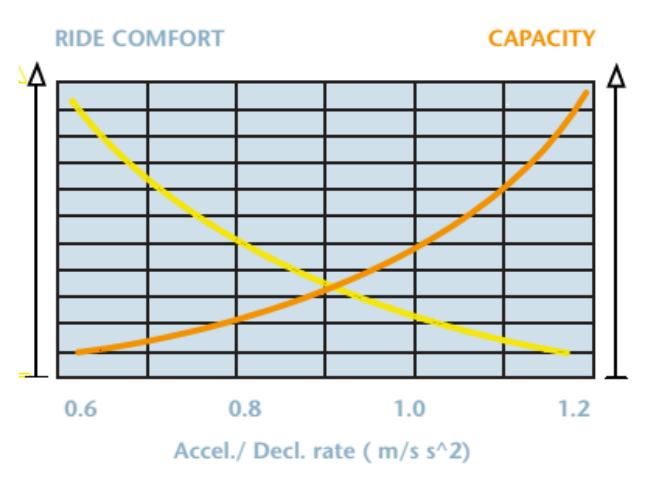

Fig 5. Threshold of comfort and discomfort in Kone elevator.

To solve the problem of measuring the vibration, noise, then analyze the vibration signal and compare with the criteria (Fig. 5), the installer uses Kone equipment to measure and analyze the vibration signal. This equipment shows the result of the good or bad elevator.

Now, the Kone manufacturer designs the connection between an accelerometer and consumer computer (Fig. 6). Thus, the Kone elevator can be installed by other elevator companies and the customer is easy to approach the Kone criteria. The elevator can be installed by other elevator companies and the customer is easy to approach the Kone criteria.

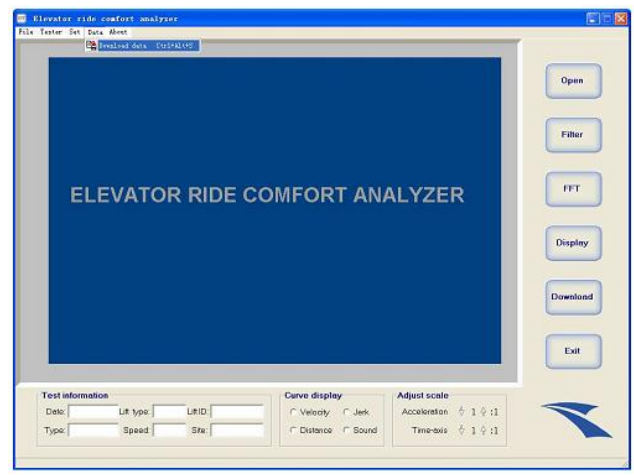

Fig 6. The interface between accelerometer and computer.

\section{EXPERIMENTS OF MEASURING THE VIBRATION.}

In the experiment, a Vietnamese famous band elevator is chosen for measuring the vibration. A test is experimented in an elevator test tower in Long An Province, Vietnam. The 3 axis acceleration was put on the floor of the elevator. The result of acceleration amplitude is shown in Fig. 8.

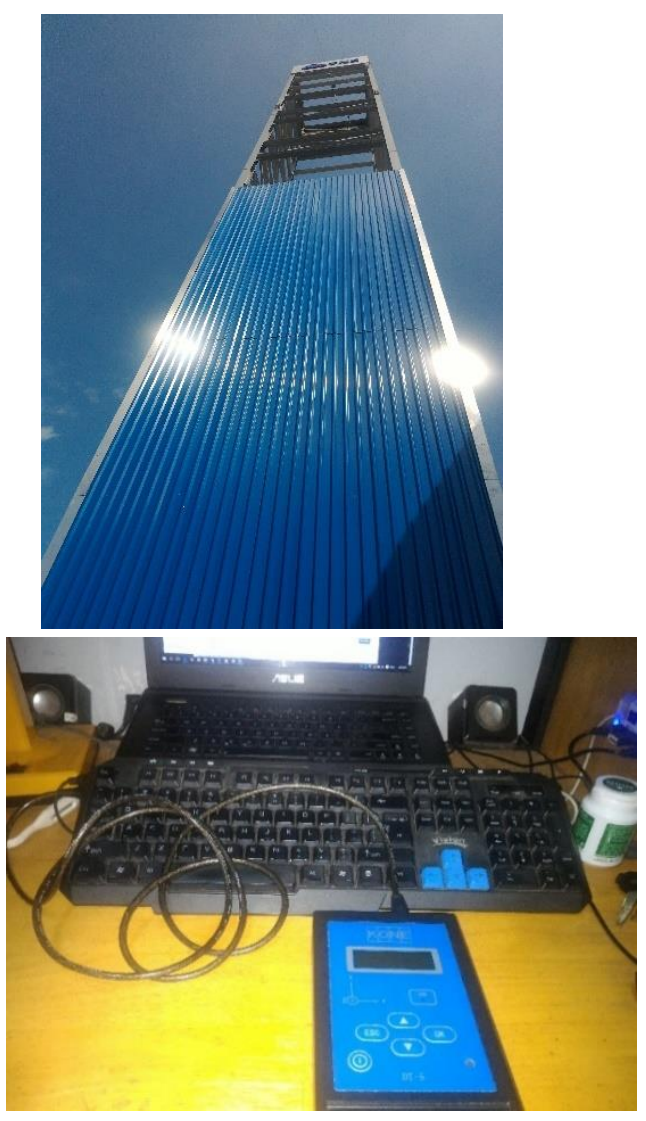

(a)

Fig 7. Elevator test tower in Long An province (a) and 3 axis accelerometer (b).

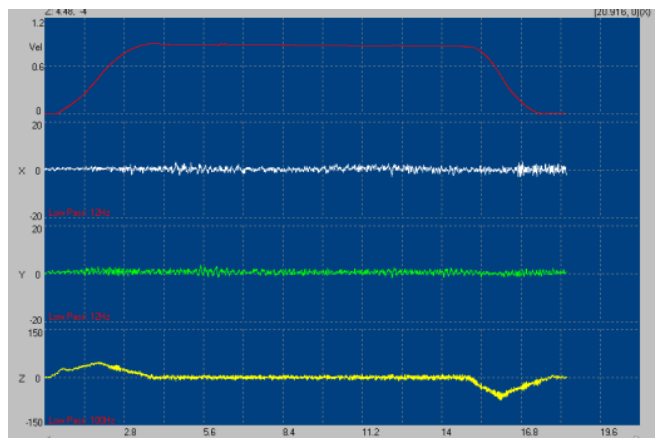

Fig 8. Acceleration amplitude on 3 axis

From the result of acceleration amplitude of 3 axis $\mathrm{X}, \mathrm{Y}, \mathrm{Z}$, the FFT is used to invert time domain of acceleration into the frequency domain. The result is showed in fig. 9. This result is compared with the criteria of elevators. If the acceleration amplitude is under the line of criteria, this elevator is acceptable to use. 


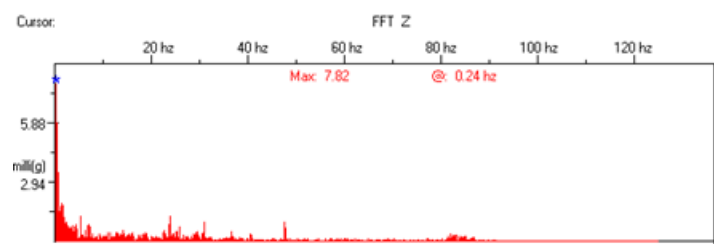

Fig 9. Result of inversion from time domain into frequency domain

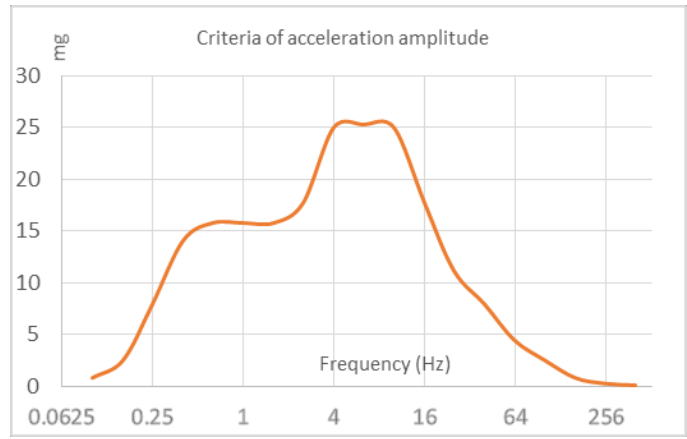

Fig 10. Change unit of fig. $4 \mathrm{~b}$ from $\mathrm{dB}$ to $\mathrm{mg}$

In the result of experiment, we compare results in Fig. 9 with criteria of Schindler in Fig. 4. However, the unit in the Schindler's criteria is in Decibel. Thus, the fig. 10 is redrawn with y axis of $\mathrm{mg}$ and $\mathrm{x}$ axis of hertz, where $\mathrm{g}$ is gravitational acceleration. Let compare two fig 9 and 10, the experimental acceleration amplitude is under boundary of criterion. Therefore, the experimental elevator is acceptable.

\section{CONCLUSION}

The elevator can be tested for comfort. With only 3 axis accelerometer connected with a computer, Vietnamese elevator manufacturer can know elevators manufactured are acceptable or not when these elevators are compared with foreign elevators about smooth and comforable. Besides, the 3 axis accelerometers are cheap, the Vietnamese factories can equip installers with them.

With easy measuring method and cheap equipment, Vietnam elevator factory can ensure high quality, comfortable elevators. In addition, the manufactured elevators are enough criteria to export.
[1]. Mason Industries (Hong Kong) Limited, Noise and Vibration Control at High Speed Elevators.

[2]. Shinichi Noda, Sueyoshi Mizuno, Yoshitake Kamijo, Makoto Matsushita, "Prediction of Room Noise Caused by Vibration of High Power Elevator Traction Machine", The Proceedings of the Transportation and Logistics Conference, vol. 2012.21, pp. 41-44, 2012.

[3]. Hioky, Measure the Vibration of an Elevator, 2011.

[4]. Young-Min Lee, Jun-Koo Kang and Seung-Ki Sul, "Acceleration Feedback Control Strategy for Improving Riding Quality of Elevator System". in Conference Record - IAS Annual Meeting (IEEE Industry Applications Society), vol. 2, pp. 1375-1379, 1999.

[5]. Jong-ho Baek, Mark H. Hansen, Robert L. Nigbor, and Salih Tileylioglu, "Elevators as an excitation source for structural health monitoring in buildings", 4th World Conference on Structural Control and Monitoring, July 2006.

[6]. Yoshiaki Yamazaki, Masao Tomisawa, Kouji Okada, Yoshiki Sugiyama, "Vibration control of Super High Speed Elevators", JSME International Journal, 1997.

[7]. I. Hostens, H. Ramon, "Descriptive analysis of combine cabin vibrations and their effect on the human body", Journal of Sound and Vibration, 2003.

[8]. M. J. Griffin, Handbook of Human Vibration, Academic Press, 1990.

[9]. Schindler Passenger Elevators, Schindler $3300 /$ Schindler 5300 Information on noise and vibration.

Luu Thanh Tung born in Hanoi in 1972, received Engineering Engineer degree in 1994 and Master degree in 2001 at Ho Chi Minh city University of Technology. He received a $\mathrm{PhD}$ degree in Mechanical Engineering at the University of Ulsan - Korea.

Associate Professor, Doctor Luu Thanh Tung is currently teaching at the Ho Chi Minh City University of Technology from 2003 to present. Currently, he is the Head of Department of Contruction Machinery and Handling Equipment. The main research direction is the oscillation of the Heavy lifting equipment and specialized equipment.

\section{REFERENCES}




\title{
Nghiên cứu về ngưỡng dao động trong thang máy tại Việt nam
}

\author{
Lưu Thanh Tùng
}

Trường Đại học Bách Khoa - Đại học Quốc gia Tp.HCM

Tóm tắt- Ngày nay, thang máy đã được lắp đặt cho hầu hết các tòa nhà và chúng trở nên rất quen thuôc với mọi người trong cuộc sống hiện đại. Vì vậy, thang máy được yêu cầu phải êm và im lặng hơn. Tuy nhiên, những nhà sản xuất thang máy vẫn chưa có phương pháp và thiết bị để đo dao động trong thang máy. Bài báo này sẽ giới thiệu một phương pháp dùng gia tốc kế và FFT để ghi nhận phổ dao động. Phổ này sẽ được so sánh với phổ đã được xây dựng bởi các nhà sản xuất. Trong bài báo này, phổ tiêu chuẩn của các nhà sản xuất thang máy nổi tiếng như Kone và Schindler sẽ được giới thiệu nhằm tham khảo cho các nhà sản xuất Việt nam.

Từ khóa-FFT; biên độ dao động; 